\title{
Sub-Ambient Radiative Cooling Realized Using CaCO3 Microparticle-Based Single Layer Without Metal Reflector for Entire Day
}

\author{
Hangyu Lim \\ Korea University \\ Dongwoo Chae \\ Korea University \\ Soomin Son \\ Korea University \\ Sucheol Ju \\ Korea University \\ Jisung $\mathrm{Ha}$ \\ Korea University \\ Heon Lee ( $\nabla$ heonlee@korea.ac.kr) \\ Korea University
}

\section{Research Article}

Keywords: radiative cooling, micro-particle, broadband mid-IR emitter, atmospheric transparency window, passive cooling

Posted Date: May 24th, 2021

DOl: https://doi.org/10.21203/rs.3.rs-523745/v1

License: (9) This work is licensed under a Creative Commons Attribution 4.0 International License. Read Full License 


\section{Sub-ambient radiative cooling realized using $\mathrm{CaCO}_{3}$}

2 microparticle-based single layer without metal

3 reflector for entire day

4 Hangyu Lim, Dongwoo Chae, Soomin Son, Sucheol Ju, Jisung Ha and Heon Lee*

5 Department of Material Science and Engineering, Korea University, Anam-ro 145, Sungbuk-Gu,

6 Seoul 136-701, Republic of Korea

7 E-mail: nanoimprint@naver.com

8

9 Author information

10 Hangyu Lim: limhangyu96@gmail.com

11 Dongwoo Chae: dwc0808@korea.ac.kr

12 Soomin Son: wavry3330@naver.com

13 Sucheol Ju: vxz091@,korea.ac.kr

14 Jisung Ha: hajisung3478@korea.ac.kr

15 Heon Lee*: heonlee@korea.ac.kr 


\section{ABSTRACT}

17 Conventional cooling systems, that is, air conditioners, should be replaced because they consume

18 a substantial amount of energy and cause environmental pollution. In this context, radiative cooling

19 systems, which perform cooling without consuming any energy or causing environmental

20 pollution, are emerging as an alternative. However, most of the radiative coolers explored thus far

21 include metals, such as silver, that are used as solar reflectors, thereby entailing problems in terms

22 of practicality, mass production, cost, and light pollution. Herein, we propose calcium carbonate

$23\left(\mathrm{CaCO}_{3}\right)$ micro-particle-based radiative cooling, which utilizes the high-energy band gap of

$24 \mathrm{CaCO}_{3}$ for high-performance radiative cooling. As the cooler has only a single layer of a $\mathrm{CaCO}_{3}$

25 composite without any metal reflector, it is mass-producible, cheap, and does not cause light

26 pollution. To demonstrate the cooling performance of $\mathrm{CaCO}_{3}$, optical properties and temperature

27 changes are measured and compared with those of commercial white paint. As a result, it is

28 demonstrated that the $\mathrm{CaCO}_{3}$-based radiative cooler has cooling power $93.1 \mathrm{~W} / \mathrm{m}^{2}$ in calculation

29 and can be cooled $6.52{ }^{\circ} \mathrm{C}$ and $3.38{ }^{\circ} \mathrm{C}$ under ambient temperature in daytime and nighttime

30 respectively. Thus, it can perform as radiative cooler in entire day.

31 KEYWORDS: radiative cooling, micro-particle, broadband mid-IR emitter, atmospheric transparency window,

32 passive cooling 

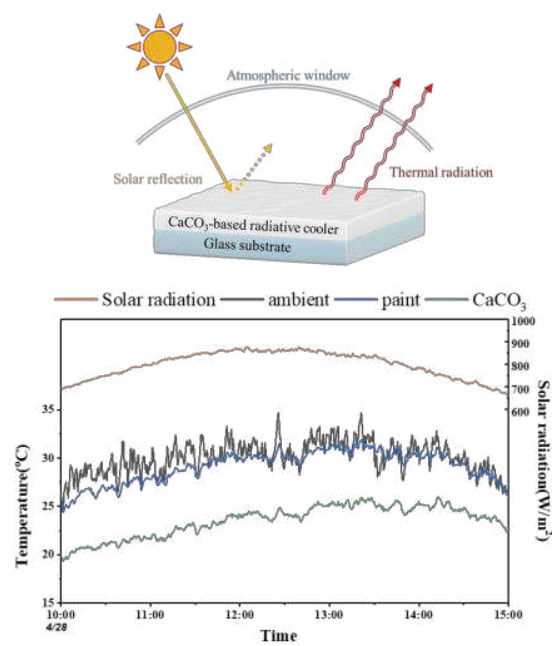

\section{1. Introduction}

35 Cooling systems are a crucial necessity in modern industrial and residential complexes.

36 Presently, most cooling systems incorporate air conditioners. However, air conditioners consume

37 large amounts of energy and are a major cause of environmental pollution, such as the emission of

38 chlorofluorocarbons, which lead to ozone depletion ${ }^{1}$. Moreover, the most of energy used to drive

39 the air conditioner obtained by consuming fossil fuels which emit greenhouse gases that cause

40 global warming. Therefore, a new type of cooling system is required. In this scenario, radiative

41 cooling is the key to an alternative cooling system. Notably, radiative cooling entails

42 thermodynamic cooling without any energy consumption. Consequently, it does not burden the

43 environment ${ }^{2,3}$. The principle of passive radiative cooling is that the system radiates its energy in

44 the form of infrared rays with a wavelength of 8-13 $\mu \mathrm{m}$ (referred to as the atmospheric window)

45 and reflects sunlight which means the system is not heated by solar radiated energy ${ }^{4,5}$. Unlike a

46 conventional cooling system that transfers heat from the inside to the outside, a radiative cooler

47 emits energy directly into space, at a temperature of $3 \mathrm{~K}$, without entailing any chemical reactions

48 or harmful effects to living beings. Because it radiates energy directly into space, it does not cause

49 global warming, in contrast with air conditioners. 
Substantial research on sub-ambient radiative cooling has been actively conducted over the past

51 few years, including investigating multilayer thin films $s^{2,5,6,7}$, polymer-based radiative coolers ${ }^{8,9,10}$,

52 and photonic material structures ${ }^{6,11,12,13}$ and their various applications ${ }^{12,14,15,16,17}$. However, most

53 radiative coolers include silver reflectors to reflect sunlight, which causes certain problems. Silver

54 is expensive and easily oxidized, and high vacuum equipment is required to deposit it. Oxidized

55 silver absorbs solar energy, which has a negative effect on radiative cooling. Using high vacuum

56 deposition, silver would be required to be deposited on a flat surface, which would impose a

57 constraint on the choice of the substrate; in addition, the process cost would also be high.

58 Furthermore, silver is a specular reflector that causes light pollution ${ }^{18}$. Smooth surface reflectors,

59 such as mirrors, reflect light parallelly, which can cause dizziness or safety hazards for pedestrians

60 and drivers. It can also damage the retina or iris, causing vision loss in certain cases. Owing to

61 these reasons, researchers have recently published radiative coolers without a metal reflector. In

62 order to reflect sunlight without a metal layer, white ceramic powders such as $\mathrm{SiO}_{2}, \mathrm{Al}_{2} \mathrm{O}_{3}$ are

63 mixed with the polymer matrix ${ }^{19,20,21}$, a porous polymer ${ }^{4}$ or a polymer composite ${ }^{22}$ is prepared to

64 induce scattering to increase the reflectivity. These can radiate and be cooled without metal

65 reflector, but because they are composed of a polymer matrix, they are susceptible to scratches due

66 to their low hardness. Therefore, in this study, the performance of a ceramic powder-based

67 radiative cooling device using $\mathrm{CaCO}_{3}$ microparticles(MPs) will be discussed.

$68 \mathrm{CaCO}_{3}$ is inexpensive and has excellent thermal and mechanical stability. Consequently, it is

69 used as a filler in several composite materials. Further, it is mainly used in plastics ${ }^{23,24,25,26}$,

70 dyes $^{27,28}$, and rubber. ${ }^{29}$ It is also widely used in agricultural chemicals ${ }^{30,31}$, medicine ${ }^{32,33}$, food ${ }^{34}$,

71 and construction materials ${ }^{35,36}$. Moreover, due to its large band gap of $5 \mathrm{eV}$, it does not absorb 
72 most of solar irradiance. We demonstrate the radiative cooling performance of $\mathrm{CaCO}_{3}$ by 73 comparing it to that of a commercial white paint. 


\section{2. Principle of radiative cooling}

75 The equation for radiative cooling is derived using the law of conservation of energy as 76 follows $^{23,37}$ :

$77 \quad P_{\text {net }}(T)=P_{\text {rad }}(T)-P_{\text {atm }}\left(T_{\text {atm }}\right)-P_{\text {sun }}-P_{\text {non-rad }}$

78 where

$79 \quad P_{\mathrm{rad}}(\mathrm{T})=\int_{0}^{2 \pi} \int_{0}^{\frac{\pi}{2}} \int_{0}^{\infty} I_{\mathrm{BB}}(T, \lambda) \varepsilon(\lambda, \theta) \cos \theta \sin \theta d \lambda d \theta d \varphi$

80 represents the hemispherical radiation power emitted from the radiative cooler.

$81 \quad P_{\text {sun }}=\int_{0}^{\infty} I_{A M 1.5}(\lambda) \varepsilon(\lambda, \theta) d \lambda$

82 is the solar irradiance power absorbed by the radiative cooler.

$83 P_{\mathrm{atm}}\left(T_{\mathrm{atm}}\right)=\int_{0}^{2 \pi} \int_{0}^{\frac{\pi}{2}} \int_{0}^{\infty} I_{\mathrm{BB}}\left(T_{\mathrm{atm}}, \lambda\right) \varepsilon(\lambda, \theta) \varepsilon_{\mathrm{atm}}(\lambda, \theta) \cos \theta \sin \theta d \lambda d \theta d \varphi$

84 is the power of the incident atmospheric radiation. According to Kirchhoff's law of thermal

85 radiation, for these equations, absorption and radiation are the same owing to thermodynamic

86 equilibrium.

$87 \quad P_{\text {non-rad }}=h_{\mathrm{c}}\left(T_{\mathrm{atm}}-T\right)$

88 denotes the power lost by the radiative cooler because of convection and conduction.

89 Here, $I_{\mathrm{BB}}$ represents the blackbody radiation intensity and is expressed using the formula

$90 I_{B B}=\left(2 h c^{2} / \lambda^{5}\right) \times\left(e^{h c / \lambda k_{B} T}-1\right)^{-1}$, and $\varepsilon_{\mathrm{atm}}(\lambda, \theta)=1-[t(\lambda)]^{1 / \cos \theta}$ represents the 
angular atmospheric emissivity, where $t(\lambda)$ denotes the atmospheric transmittance in the zenith direction. The constants $h_{c}, h, c, k_{B}$ represent the heat transfer coefficient, the Planck constant, speed of light, and Boltzmann constant, respectively. The cooling temperature is

94 defined as $\Delta T_{\text {cool }}=T-T_{\text {atm }}$, which is calculated by extracting the cooling temperature under the condition $P_{\text {net }}(T)=0$. As previously reported, $T_{\text {atm }}$ is replaced by $T_{\mathrm{amb}}{ }^{38,39}$. All the calculation processes of the net cooling power and cooling temperature were performed using MATLAB software based on absorptivity and emissivity values, with a wavelength spacing of $0.01 \mu \mathrm{m}$.

\section{Experimental}

\subsection{Source materials} 184, photoinitiator), calcium carbonate powder (20-30 $\mu \mathrm{m}$ in diameter), and 1-methyl-2pyrrolidinone (NMP) were purchased from Sigma Aldrich. For comparison, commercial white paint was acquired from Okong Company in spray form.

\subsection{Sample preparation}

$\mathrm{CaCO}_{3} \mathrm{MP}$ (5 g) was mixed in NMP (intrinsic solvent) (5 g) and stirred at $200 \mathrm{rpm}$ with a magnetic stirring bar for 30 min so that it would not agglomerate with each particle. After the powders were dispersed, the DPHA monomer (0.25 g) and UV initiator (Irgacure 184) (0.025

$111 \mathrm{~g})$ were added to the solution and stirred at $200 \mathrm{rpm}$ for $2 \mathrm{~h}$. The glass substrate was treated

112 with UV-ozone, the prepared solution was dropped on it, and the glass with the solution was 
113 heated on a $100{ }^{\circ} \mathrm{C}$ hot plate for $2 \mathrm{~h}$ to evaporate the NMP solution. After the solvent had

114 dried completely, it was exposed to a UV lamp for 30 min to polymerize the DPHA.

115 To prepare paint-coated glass, the glass was spray painted to make it approximately $200 \mu \mathrm{m}$

116 thick.

117

118 3.3. Sample Characterization

119 An X-ray powder diffraction (XRD) scan (SmartLab, Rigaku, Japan) was performed using a 120 diffractometer and a Cu target (wavelength: $1.5412 \mathrm{~A}$ ) as the X-ray source at $9 \mathrm{~kW}$. The surface

121 of the radiative cooler was observed at $15 \mathrm{keV}$ using FESEM (Regulus8100, Hitachi, Japan).

122 Optical properties within a wavelength range of 3-2.5 $\mu \mathrm{m}$ were measured using a UV-Vis-NIR

123 spectrophotometer (Solidspec-3700, Shimadzu, Japan) in the integral sphere using Spectralon

124 diffuse reflectance standards (SRS-99-010, Labsphere, USA) as a baseline reflector. The

125 optical properties of the IR spectra (wavelength range of 3-15 $\mu \mathrm{m}$ ) were measured through

126 Fourier transform infrared spectroscopy (FT-IR; Nicolet IS-50, Thermo Scientific, USA) and

127 an integral sphere (Mid-IR IntegratIRTM, PIKE technologies, USA) using an Au reflector. The

128 absorbance A was determined using the equation $\mathrm{A}=1-\mathrm{R}-\mathrm{T}$ after measuring the reflectance $\mathrm{R}$

129 and transmittance T using the equipment described.

130 4. Results and discussion 


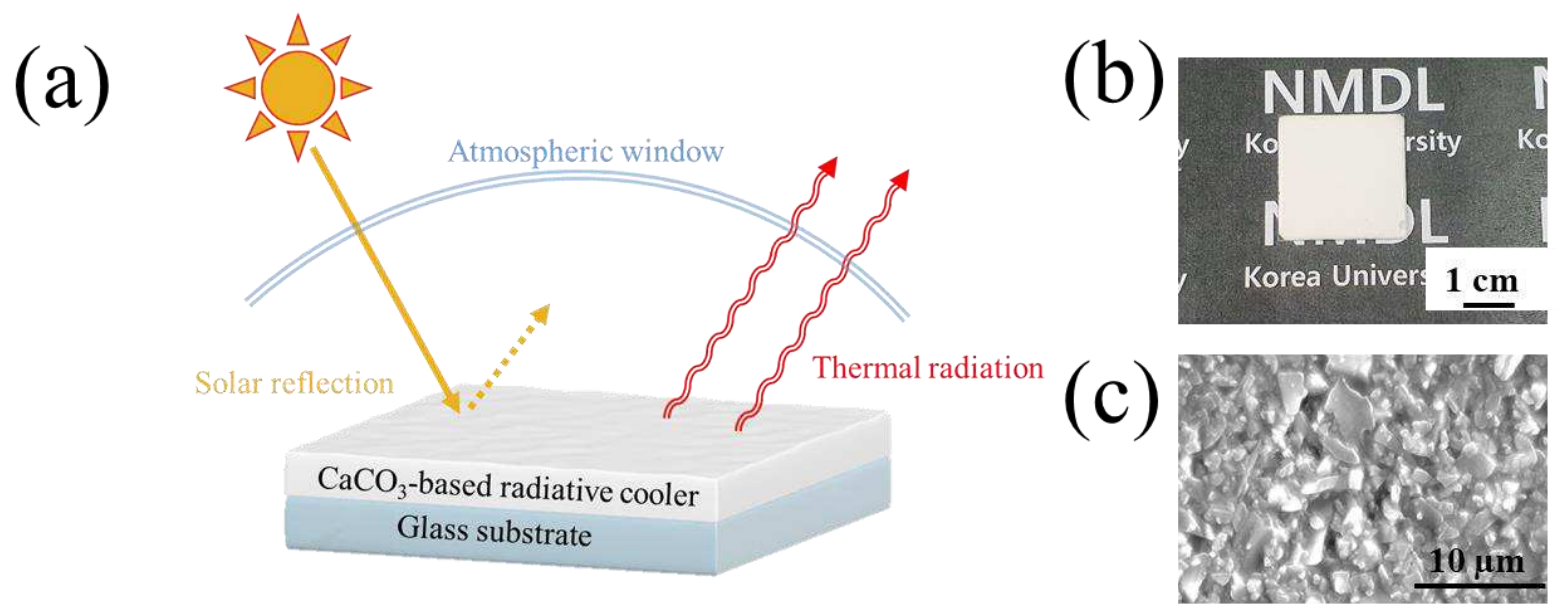

131

133

134

135

136

137

138

139

140

141

142

143

144

145

146

147

148

Figure 1. (a) Schematic of radiative cooling principle and radiative cooler structure. (b) Photo image and (c) SEM top view of radiative cooler, $\mathrm{CaCO}_{3}$-coated glass.

Figure 1(a) shows the operating principle of radiative cooling and structure of $\mathrm{CaCO}_{3}$-based radiative cooler. By reflecting sunlight, it avoids being heating and sends heat energy to the outside by radiating infrared rays in the wavelength range corresponding to the atmospheric window, cooling to a lower temperature than the ambient temperature. As depicted in Figure 1(b), the $\mathrm{CaCO}_{3}$ layer is coated on glass placed over a black background, and the letters in the background are not visible, indicating that the transmittance is sufficiently low in the visual check. Figure 1(c) displays the surface of the $\mathrm{CaCO}_{3}$ layer analyzed through field emission scanning electron microscopy (FESEM). Figure S2 depicts the absorption and transmittance of $\mathrm{CaCO}_{3}$ with the dipentaerythritol penta-/hexa-acrylate (DPHA) binder with respect to the thickness. With an increase in the thickness, the transmittance tends to decrease. However, the absorption did not increase until the thickness reached $350 \mu \mathrm{m}$. Further, at $500 \mu \mathrm{m}$, the absorption started increasing, and approximately $8 \%$ of the solar incident power was absorbed. The emissivity within the atmospheric window region does not differ significantly based on the thickness. The ratio of absorbed solar incident power, average emissivity in the atmospheric 
149 window region, and calculated net cooling power at $300 \mathrm{~K}$ in accordance with the thickness

150 are listed in Table S1. The cooling power is the highest at a thickness of $130 \mu \mathrm{m}$; however,

151 because the transmittance in the solar radiation region is greater than $5 \%$, the thickness of 350

$152 \mu \mathrm{m}$, at which the transmittance is low and the absorption does not increase significantly, is

153 considered to be the most suitable and is adopted as the thickness used in this experiment.

(a)

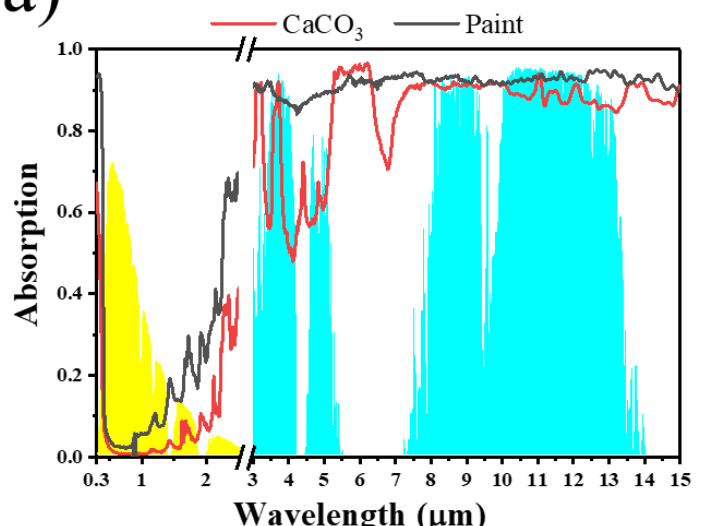

(b)

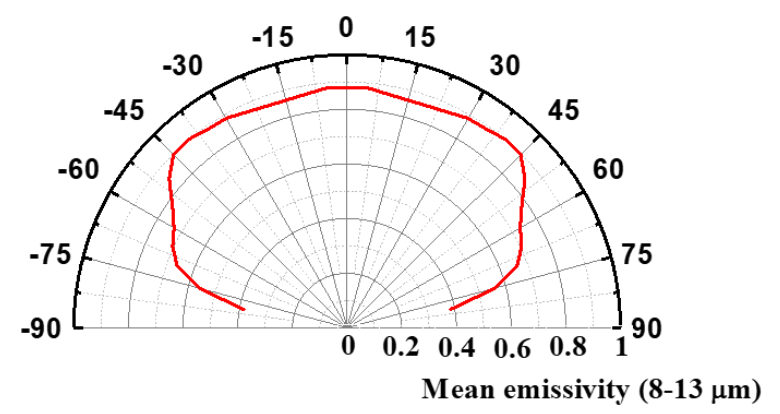

Figure 2. (a) Spectral absorptivity and emissivity of $\mathrm{CaCO}_{3}$ - and commercial white-paint-coated glass. (b) Average emissivity of $\mathrm{CaCO}_{3}$-coated glass in the atmospheric window $(8-13 \mu \mathrm{m})$ with respect to angle $\theta$.

157 Figure 2(a) presents the absorption properties of $\mathrm{CaCO}_{3}$ and white-paint-coated glass. In the atmospheric window region, $\mathrm{CaCO}_{3}$ and the paint have emissivities of $89.6 \%$ and $92.7 \%$, respectively. The paint has a slightly better emissivity property. However, in the solar radiation region, $\mathrm{CaCO}_{3}$ has better absorption properties than the paint. $\mathrm{CaCO}_{3}$ absorbs $4.1 \%$ of the solar incident power, whereas the paint absorbs $11.1 \%$. This difference in solar absorbption affects

162 the cooling performance. Using these optical properties, at $300 \mathrm{~K}$, the net cooling power was calculated as $93.1 \mathrm{~W} / \mathrm{m}^{2}$ for $\mathrm{CaCO}_{3}$ and $38.6 \mathrm{~W} / \mathrm{m}^{2}$ for paint. The calculation shows that $\mathrm{CaCO}_{3}$ demonstrates 2.4 times higher cooling performance than the paint. The ratio of absorbed solar incident power, average emissivity in the atmospheric window region, and net cooling power are presented in Table 1. Figure 2(b) depicts the average emissivity in the atmospheric window 
167 region in accordance with the incident light angle. The decrease in emissivity starts at 168 approximately $50^{\circ}$, and the emissivity remains greater than $70 \%$ until the angle of $70^{\circ}$ is 169 reached.

170

Table 1. Average absorption $(0.3-2.5 \mu \mathrm{m})$, emissivity $(8-13 \mu \mathrm{m})$ and net cooling power at $300 \mathrm{~K}$

\begin{tabular}{cccc}
\hline Sample & $\begin{array}{c}\text { Solar power absorption ratio } \\
(0.3-2.5 \mu \mathrm{m})\end{array}$ & $\begin{array}{c}\text { Average emissivity } \\
(8-13 \mu \mathrm{m})\end{array}$ & $\begin{array}{c}\text { Net cooling power at } 300 \mathrm{~K} \\
\left(\mathrm{~W} / \mathrm{m}^{2}\right)\end{array}$ \\
\hline $\mathrm{CaCO}_{3}$ & 0.041 & 0.896 & 93.1 \\
paint & 0.111 & 0.927 & 38.6
\end{tabular}

171

172

173

174 
(a)

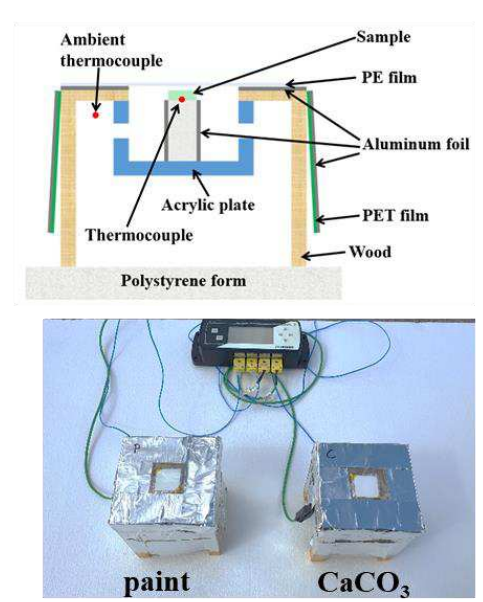

(c)

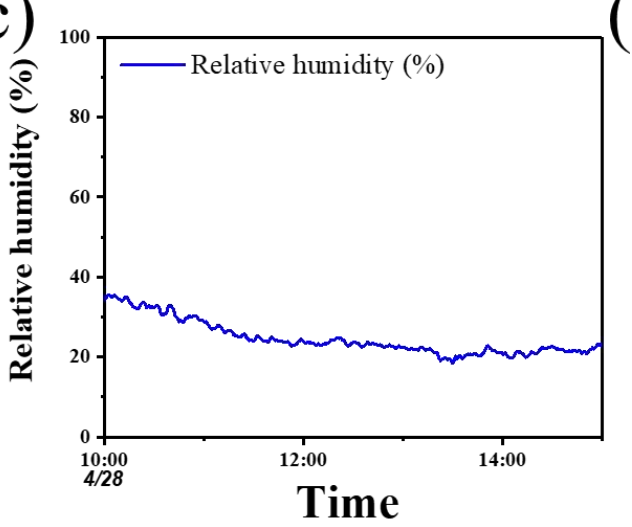

(b)

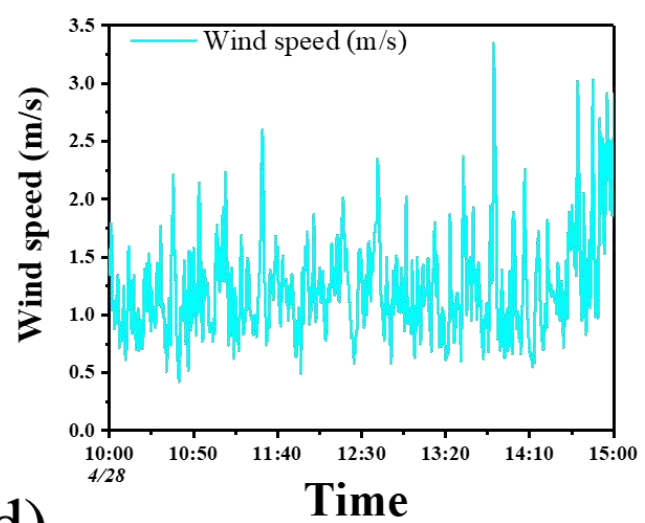

(d)

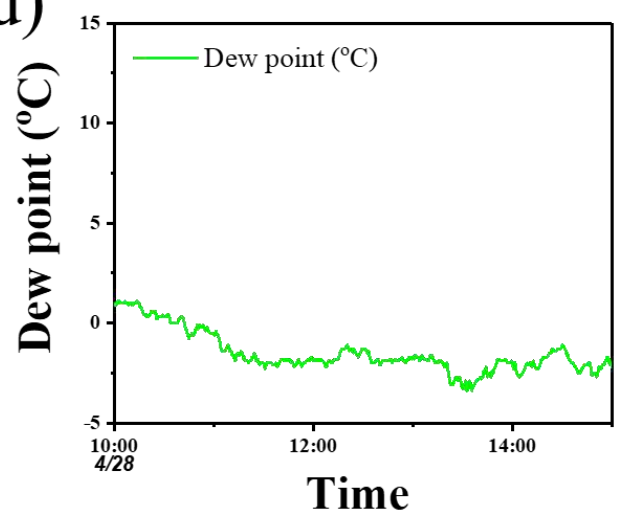

(e)

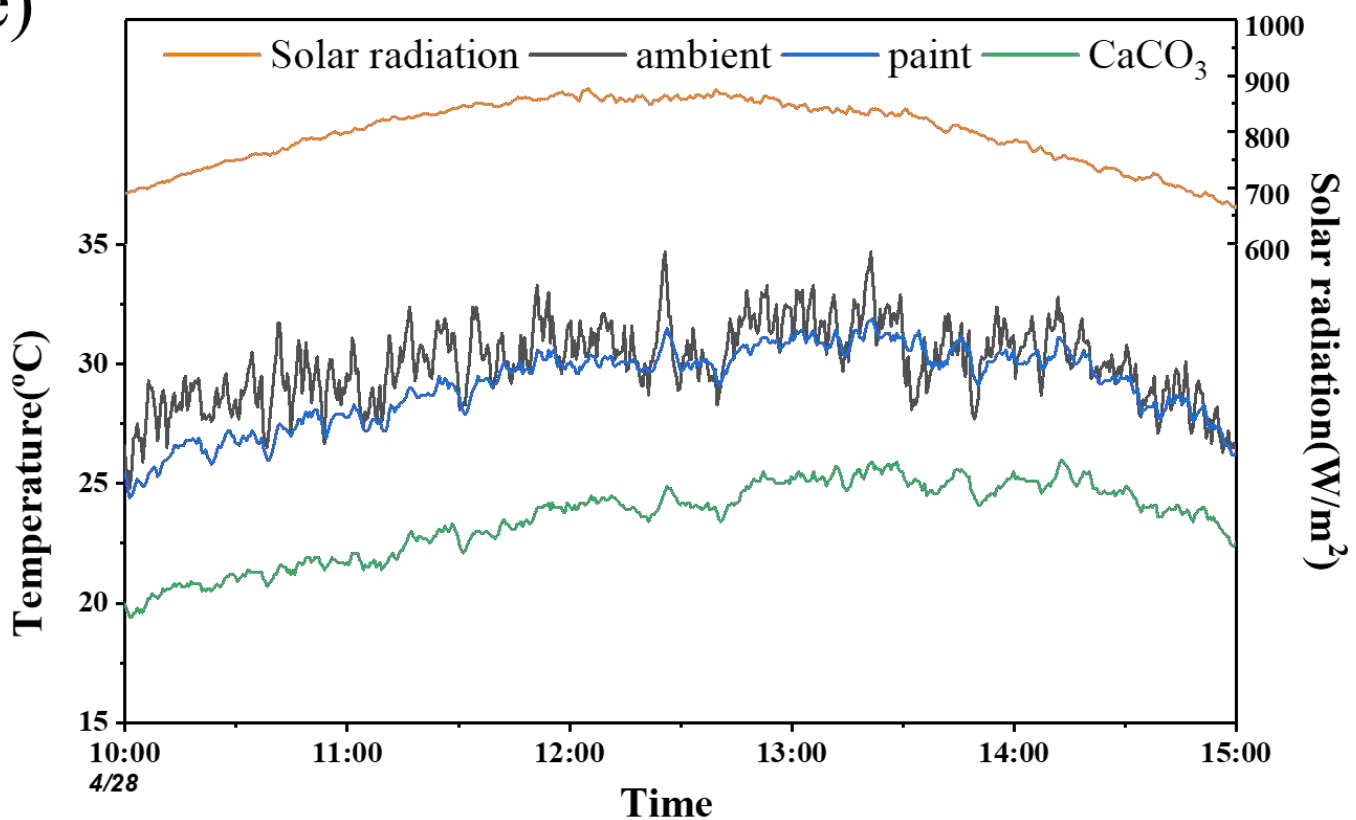

Figure. 3. (a) Schematic diagram and photo image of outdoor measurement system for radiative cooling. 177 Environmental conditions (b) wind speed, (c) Relative humidity, (d) dew point. (e) Radiative cooling performance of $\mathrm{CaCO}_{3}$ and white paint in terms of temperature in daytime. 
180 To measure the variation in the temperature of the surroundings over time, a measurement

181 chamber was prepared. A schematic of the chamber is presented in Figure 3(a). Acrylic plates 182 are attached to a frame made of wood, except for the top side of the frame. To prevent 183 conduction between the chamber frame and radiative cooler, a polystyrene pillar was attached 184 to the center of the acrylic plate, and a radiative cooler sample with K-type adhesive 185 thermocouples (ST-50, RKC INSTRUMENT INC., Japan) attached to the floor was placed on 186 the pillar. Several holes were drilled into the sides of the acrylic plates to allow the air to reach an ambient temperature similar to the outside temperature; further, to reduce the influence of wind, Polyethlene Terephthalate (PET) films were attached to the side of the frame. The top side of the chamber was covered with low-density polyethylene (LDPE) to maximize radiative

190 cooling effect by preventing the influence of the wind, but light of almost all wavelengths could

191 be transmitted through the top side ${ }^{4041}$. Finally, all the sides of the chamber were covered with 192 aluminum tape to reflect the light and prevent the chamber from being heated by the incident solar radiation. A copper wire thermocouple was attached to the inside of the PET film, such

194 that the tip of the wire did not contact anything, to measure the ambient temperature. Although 195 the LDPE film has excellent transmittance, it does not have perfect transmittance, as depicted 196 in Figure S3(d), which causes a greenhouse effect that increases the inner temperature. Because 197 of the greenhouse effect, holes were drilled into the acryl plates to maintain a temperature similar to that of the surroundings. The measurements were conducted on the roof of a new engineering hall at Korea University, Seoul, South Korea. The temperature of the samples and

200 the ambient temperature were recorded every $30 \mathrm{~s}$ using a data logger (OM-CP-OCTTEMP-A,

201 OMEGA Engineering, USA). The solar irradiance, wind speed, relative humidity, and dew point were also recorded every $30 \mathrm{~s}$ through a weather station (HD52.3D, DeltaOHM, Italy). 
203 Figure 3(b), (c), and (d) depict the external daytime environmental conditions of wind speed, 204 relative humidity, and dew point data, respectively, over time. The temperature variations in 205 the $\mathrm{CaCO}_{3}$ - and paint-coated glasses, ambient temperature, and solar irradiation power from 206 10:00 to 15:00 are depicted in Figure 3(e). The figures indicate that the weather is clear, not 207 cloudy, and that the fluctuation in solar irradiation is not large. The temperature of the paint208 coated glass was lower by an average of $0.93{ }^{\circ} \mathrm{C}$ when compared with the ambient temperature 209 from 10:00 to 15:00. This cooling is not significantly meaningful, as the difference in

210 temperature was less than $1{ }^{\circ} \mathrm{C}$. On the other hand, the temperature of the $\mathrm{CaCO}_{3}$-coated glass

211 was lower than the ambient temperature by an average of $6.52{ }^{\circ} \mathrm{C}$ during the same time. Based 212 on optical properties, it is clear that paint can emit more energy than $\mathrm{CaCO}_{3}$ through the 213 atmospheric window. However, it absorbs a substantial amount of solar radiated power, which 214 negatively affects the radiative cooling performance. On the other hand, although $\mathrm{CaCO}_{3}-$ 215 coated glass has lower emissivity than paints, it absorbs less solar radiated power. Therefore, $216 \mathrm{CaCO}_{3}$ can exhibit more cooling than that shown by paint under incident solar radiation. 
(a)
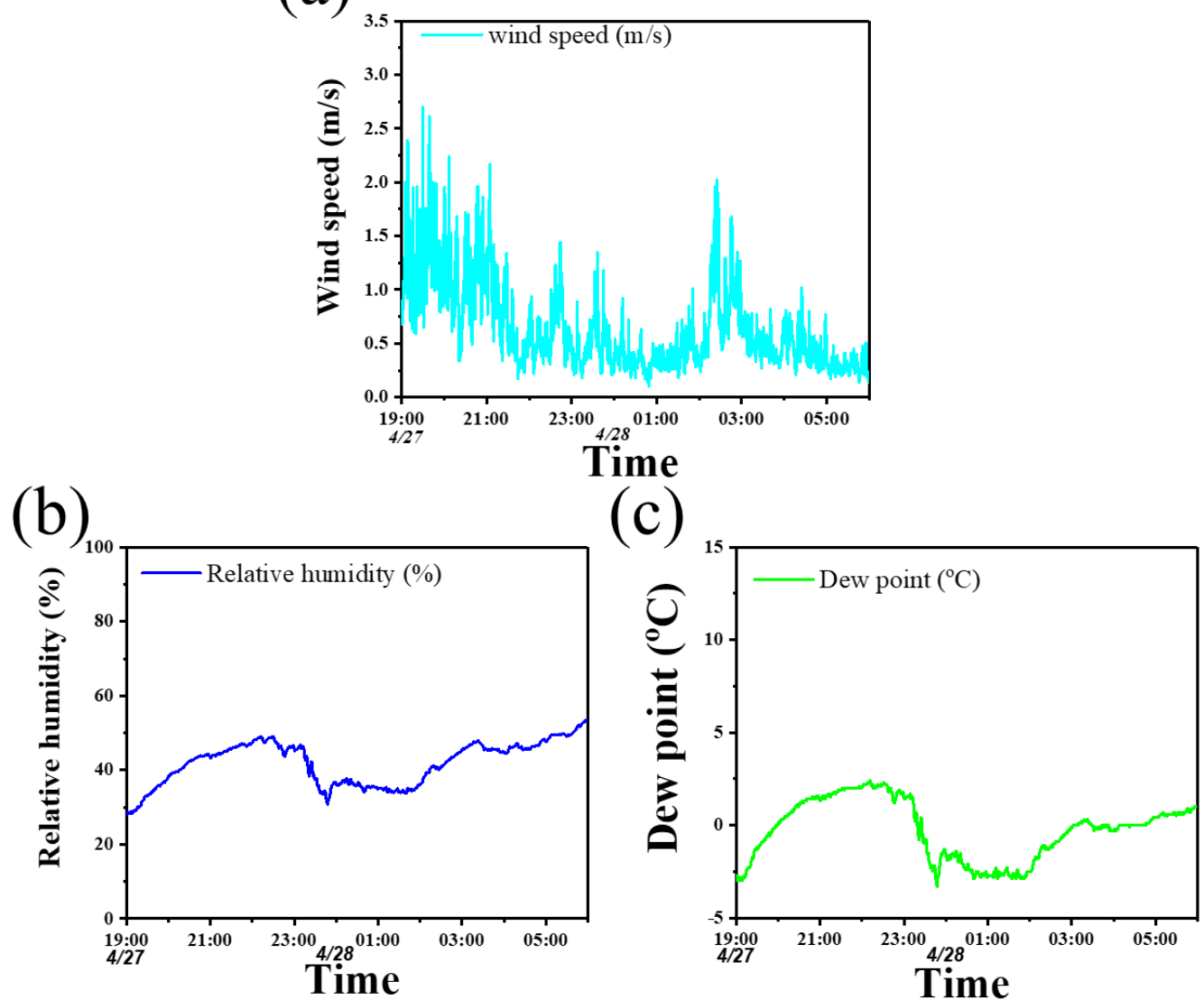

(d)

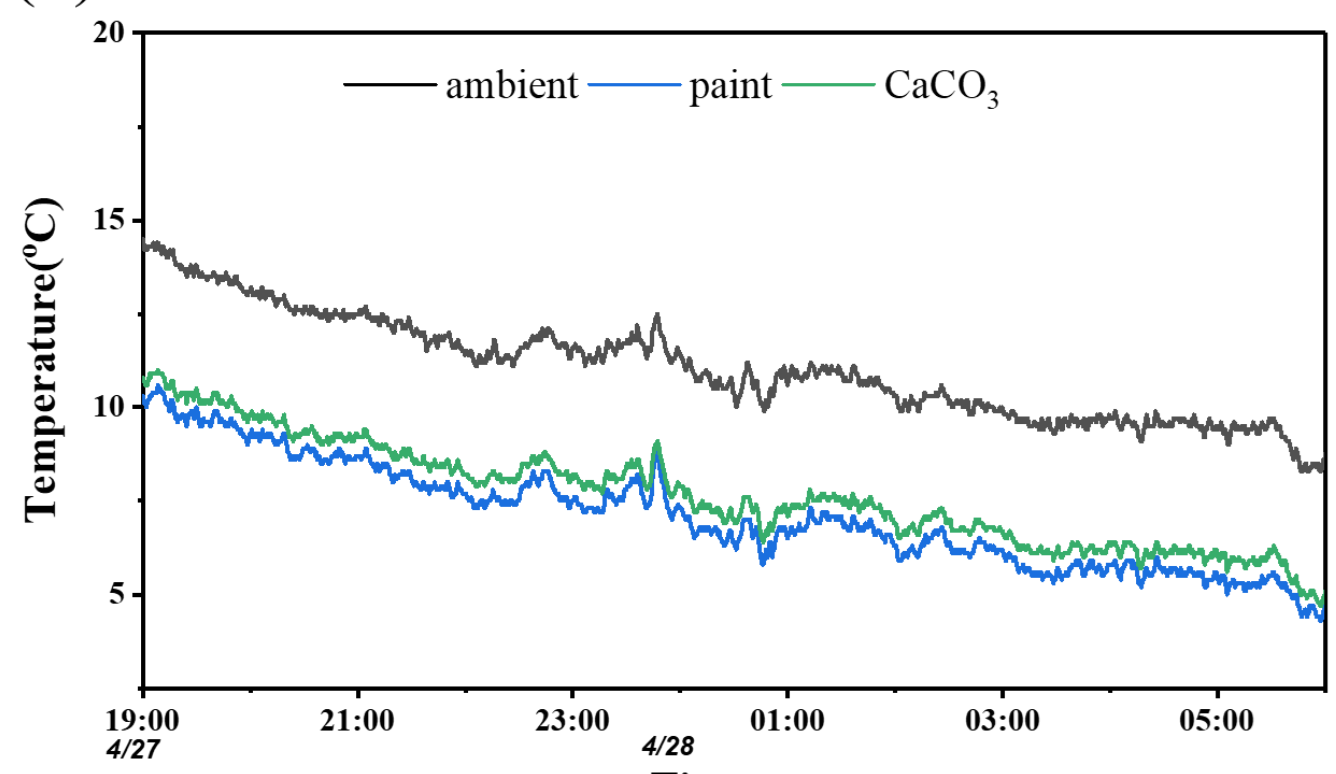

Time

Figure. 4. Environmental conditions (a) wind speed, (b) Relative humidity, (c) dew point. (d) Radiative cooling performance of $\mathrm{CaCO}_{3}$ and white paint in terms of temperature in nighttime. 
221 Similarly, the wind speed, relative humidity, and dew point at nighttime (19:00 to 5:00) are

222 presented in Figure 4(a), (b), and (c), respectively. Figure 4(d) depicts the radiative coolers and

223 the ambient temperature. Because it is nighttime, the solar irradiance is 0 , and the heating

224 caused by solar irradiance does not affect the performance of radiative cooling: only emission

225 does. Therefore, paint, which has a higher emissivity than that of $\mathrm{CaCO}_{3}$, exhibits slightly

226 better cooling performance- $-\mathrm{CaCO}_{3}$ cooled by $3.38{ }^{\circ} \mathrm{C}$ and paint cooled by $3.93{ }^{\circ} \mathrm{C}$. The

227 average cooling temperatures of the $\mathrm{CaCO}_{3}$ - and paint-coated glasses during daytime and 228 nighttime are listed in Table 2. The values indicate that both the samples can exhibit cooling to below the ambient temperature during both daytime and nighttime.

Table 2. Average cooling temperature in daytime and nighttime.

\begin{tabular}{ccc}
\hline Sample & $\begin{array}{c}\text { Average cooling temperature } \\
(10: 00-15: 00)\end{array}$ & $\begin{array}{c}\text { Average cooling temperature } \\
\end{array}$ \\
\hline paint & $-0.93{ }^{\circ} \mathrm{C}$ & $-3.93{ }^{\circ} \mathrm{C}$ \\
$\mathrm{CaCO}_{3}$ & $-6.52{ }^{\circ} \mathrm{C}$ & $-3.38^{\circ} \mathrm{C}$
\end{tabular}


(a)

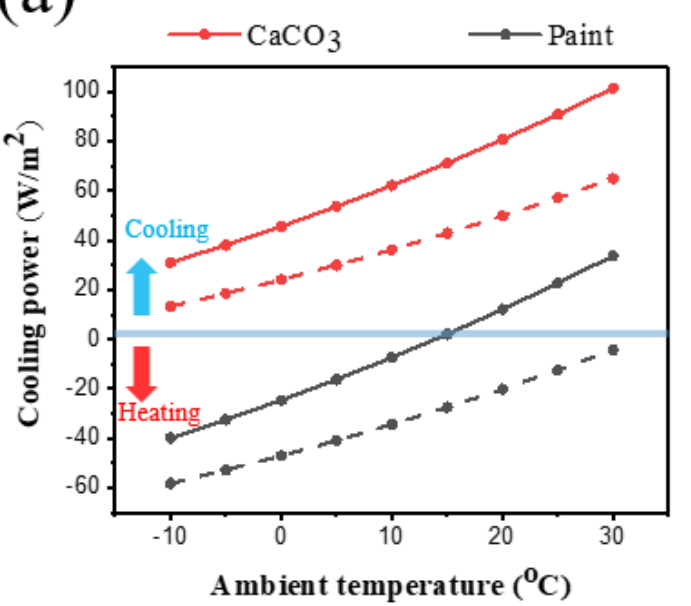

(c)

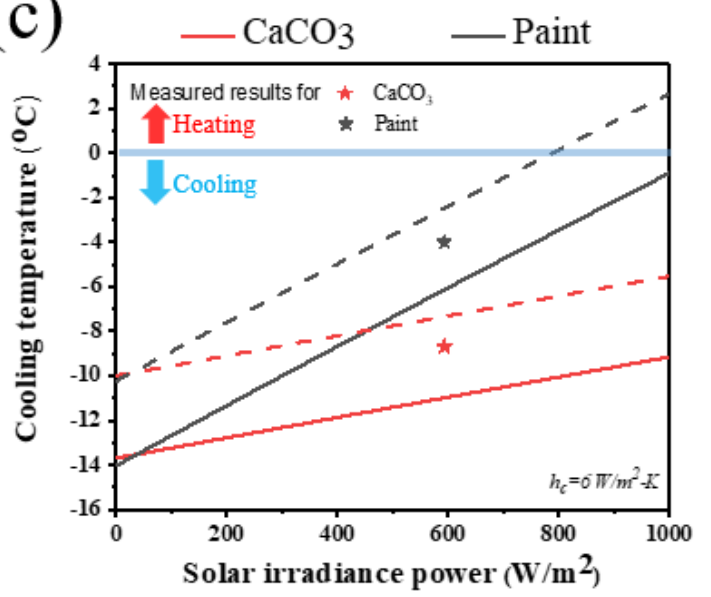

(b)

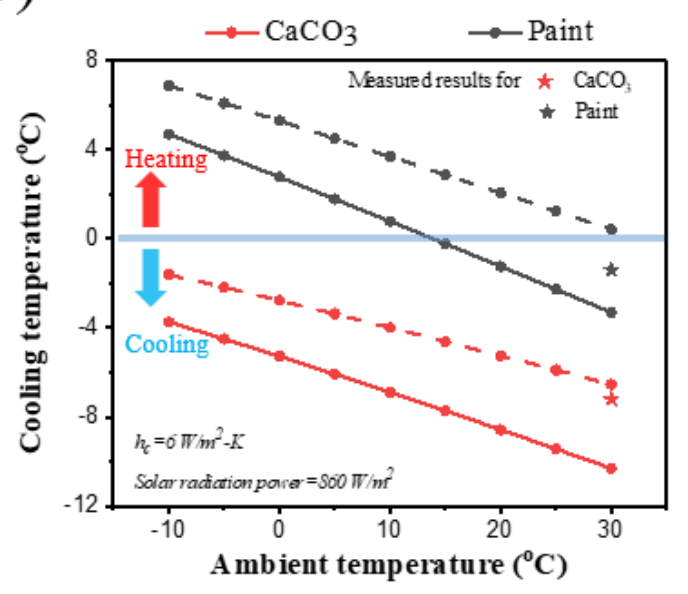

(d)

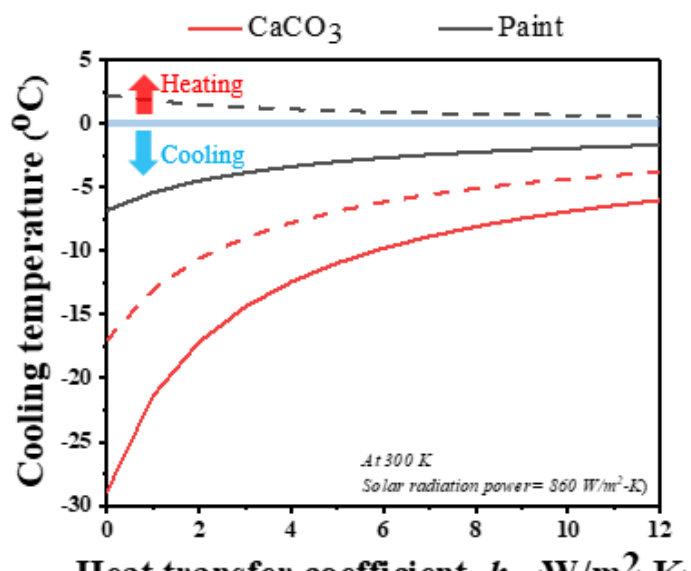

Figure. 5. (a) Calculated cooling power of $\mathrm{CaCO}_{3}$ and (b) cooling temperature in accordance with ambient temperature under the condition of $h_{c}=6 \mathrm{~W} / \mathrm{m}^{2}-\mathrm{K}$ using ideal (solid line) and mid-latitude winter (dotted line) atmospheric transmittance and measured cooling temperatures are represented with stars (red for $\mathrm{CaCO}_{3} / \mathrm{glass}_{\text {, }}$ gray for paint/glass). (c) Calculated temperatures of $\mathrm{CaCO}_{3}$ - and paint-coated glass in accordance with the solar irradiance power under the condition of $h_{c}=6 \mathrm{~W} / \mathrm{m}^{2}-\mathrm{K}$ and measured cooling temperatures are marked with stars (red for $\mathrm{CaCO}_{3}$, gray for paint). (d) Calculated temperatures of $\mathrm{CaCO}_{3}$ - and paint-coated glass in accordance with convection coefficient $h_{c}$ at $300 \mathrm{~K}$ using AM1.5 solar irradiance spectrum using ideal (solid line) and mid-latitude (dotted line) atmospheric transmittance.

Figure 5(a) and (b) depict the calculated cooling power and temperature in accordance with the ambient temperature at a steady state. The solar irradiance density and atmospheric transmittance used in the calculation are depicted in Figure S3. The heat transfer coefficient is assumed to be $6 \mathrm{~W} / \mathrm{m}^{2}-\mathrm{K}$ in consideration of the wind speed (about 1-1.5 m/s) in Figure 3(b) under condition of the wind cover according to the literature equation ${ }^{40}$. Under ideal transmittance, $\mathrm{CaCO}_{3}$ and the paint can cool by approximately $10{ }^{\circ} \mathrm{C}$ and $4{ }^{\circ} \mathrm{C}$, respectively, 
and they have cooling powers of 93.1 and $38.6 \mathrm{~W} / \mathrm{m}^{2}$, respectively, at $300 \mathrm{~K}$. However, the measured results indicate a lower cooling performance when compared with the calculated results. This is attributed to the effect of the weather at the time of the measurement and the climatic characteristics of the mid-latitude region as well as the LDPE film, which make the atmospheric transmittance lower than the ideal one. Based on the mid-latitude atmospheric transmittance obtained by calculation using MODTRAN 6, the results indicate that $\mathrm{CaCO}_{3}$ and the paint can cool by approximately 6 and $0.6{ }^{\circ} \mathrm{C}$, respectively, and that they have cooling powers of 60 and $6 \mathrm{~W} / \mathrm{m}^{2}$, respectively. Compared with the actual measurement, these results indicate a more similar cooling performance when using the mid-latitude atmospheric transmittance, in contrast with the results obtained assuming ideal transmittance. Owing to the difference between the assumed $\left(888 \mathrm{~W} / \mathrm{m}^{2}\right)$ and actual solar irradiances $\left(<888 \mathrm{~W} / \mathrm{m}^{2}\right)$, the measured cooling temperature is slightly higher than the calculated data. According to the Stefan-Boltzmann law, the total energy radiated from a blackbody is proportional to the fourth power of temperature. As depicted in Figure 3 and Figure 4, even though there is no sunlight at night, the cooling temperature is less than that during the daytime because, based on this law, the cooler radiates less energy. Figure 5(a) and (b) also indicate the same tendency, in accordance with this law. Figure 5(c) depicts the cooling temperature with respect to the solar irradiance power using ideal and mid-latitude atmospheric transmittance with a heat transfer coefficient of $6 \mathrm{~W} / \mathrm{m}^{2}-\mathrm{K}$. When the solar irradiance power is zero, $\mathrm{CaCO}_{3}$ can cool to approximately $14{ }^{\circ} \mathrm{C}$ below ambient temperature under ideal atmospheric transmittance and to $10{ }^{\circ} \mathrm{C}$ below ambient temperature under mid-latitude transmittance, and the paint can cool to

267 almost the same extent as $\mathrm{CaCO}_{3}$ at $300 \mathrm{~K}$. Because there is no sunlight, only emissivity in the atmospheric window affects the radiative cooling performance. Therefore, compared with

$269 \mathrm{CaCO}_{3}$, the paint, which has higher average emissivity of $3 \% \mathrm{p}$, can cool slightly more. 
270 However, as the solar irradiance power increases, the temperatures of $\mathrm{CaCO}_{3}$ and the paint 271 differ gradually. When solar irradiance power reaches $1000 \mathrm{~W} / \mathrm{m}^{2}, \mathrm{CaCO}_{3}$ can cool by 272 approximately $9{ }^{\circ} \mathrm{C}$ under ideal transmittance and by $5.3{ }^{\circ} \mathrm{C}$ under mid-latitude transmittance;

273 further, the paint can cool by $2.6{ }^{\circ} \mathrm{C}$ under ideal transmittance, and its temperature increases

274 to $1{ }^{\circ} \mathrm{C}$ under mid-latitude transmittance. Under strong solar irradiance, not only the emissivity

275 in the transmittance window but also the ability to reflect sunlight is significant. Therefore, It

276 is demonstrated that $\mathrm{CaCO}_{3}$ has much better cooling performance than paint as the solar 277 irradiance power increases. There are slight differences between the calculated and measured 278 data because the actual and calculated values of the atmospheric transmittance and heat transfer 279 coefficient differ. Figure 5(d) depicts the cooling temperature of the $\mathrm{CaCO}_{3}$ - and paint-coated 280 glasses in accordance with the heat transfer coefficient, $h_{c}$, under the solar irradiance power of $281888 \mathrm{~W} / \mathrm{m}^{2}$. When $h_{c}=0$, which is similar to the case of vacuum, $\mathrm{CaCO}_{3}$ can cool by $28^{\circ} \mathrm{C}$ 282 under ideal transmittance and by $16{ }^{\circ} \mathrm{C}$ under mid-latitude transmittance, and the paint can cool 283 by $10{ }^{\circ} \mathrm{C}$ under ideal transmittance and by $0.7{ }^{\circ} \mathrm{C}$ under mid-latitude transmittance. As the 284 value of $h_{c}$ increases, parasitic heat exchange occurs in the ambient environment and reduces 285 the cooling performance. Even when $h_{c}=12 \mathrm{~W} / \mathrm{m}^{2}-\mathrm{K}$, at which heat exchange occurs actively 286 via conduction and convection, $\mathrm{CaCO}_{3}$ can cool by $6{ }^{\circ} \mathrm{C}$ under ideal transmittance and by $4{ }^{\circ} \mathrm{C}$

287 under reduced transmittance. In contrast, the paint cooled by $2.4{ }^{\circ} \mathrm{C}$ under ideal transmittance, 288 and even at the reduced transmittance in $h_{c}$ value is 0 , it cooled by less than $1{ }^{\circ} \mathrm{C}$ because it 289 exhibits substantial absorption of solar irradiance. Thus, both actual measurements and calculations show that $\mathrm{CaCO}_{3}$ demonstrates better cooling performance than the paint. 


\section{Conclusions}

292 In this work, we demonstrated the radiative cooling performance of $\mathrm{CaCO}_{3}$ microparticles both

293 by calculation and experiment. As the proposed device has a powder-based layer, the scattering

294 effect maximizes the reflectance for solar irradiance wavelengths; further, owing to the intrinsic

295 optical properties of $\mathrm{CaCO}_{3}$, this device can emit energy in the form of infrared $(8-13 \mu \mathrm{m})$

296 rays. Notably, this device absorbs only $4 \%$ of the radiated solar power and exhibits an average

297 emissivity of approximately $90 \%$ in the atmospheric window. Through actual measurements

298 of temperature variations, it is demonstrated that the $\mathrm{CaCO}_{3}$ radiative cooler can cool by 6.5

$299{ }^{\circ} \mathrm{C}$ during the daytime and by $3.4{ }^{\circ} \mathrm{C}$ during nighttime. Further, according to calculations, it can

300 cool by more than $10{ }^{\circ} \mathrm{C}$ during daytime. Furthermore, this structure, $\mathrm{CaCO}_{3}$ composite single

301 layer, does not contain any metal layer as reflector, which enhances productivity, price

302 competitiveness and practicality. These results demonstrate that the proposed $\mathrm{CaCO}_{3}$ can be

303 employed as a radiative cooler itself. Owing to the property of $\mathrm{CaCO}_{3}$, it can be radiative cooler

304 as tile of paint forms and can be applied to building, car, cool bag or other any fields that need 305 being cooled.

306 Associated content

307 Supporting Information

$308 \mathrm{XRD}$ results for $\mathrm{CaCO}_{3}$ powders; Optical properties of $\mathrm{CaCO}_{3}$-based radiative cooler in

309 accordance with thickness; Solar power density and atmospheric transmittance window

\section{Corresponding Authors}

311 E-mail: nanoimprint@naver.com.

\section{CRediT authorship contribution statement}


313 Hangyu Lim: Conceptualization, Methodology, Writing-Original draft, Visulization, Formal 314 analysis, Investigation. Dongwoo Chae: Conceptualization, Software, Validation. Soomin 315 Son: Resources, Methodology. Sucheol Ju: Data Curation. Jisung Ha: Investigation. Heon 316 Lee: Supervision

\section{Acknowledgements}

318 This research was supported by Creative Materials Discovery Program through the National

319 Research Foundation of Korea(NRF) funded by Ministry of Science and ICT (NRF320 2018M3D1A1058972). This work was supported by the National Research Foundation of

321 Korea(NRF) grant funded by the Korea government(MSIT) (No. 2020R1A2C3006382). This

322 research was supported by the International Research \& Development Program of the National

323 Research Foundation of Korea (NRF) funded by the Ministry of Science and ICT (Grant 324 number: 2019K1A47A02113032 )

\section{References}

326 1. EPA. Phaseout of Ozone-Depleting Substances. US Environ. Prod. Agency (2016).

2. Raman, A. P., Anoma, M. A., Zhu, L., Rephaeli, E. \& Fan, S. Passive radiative cooling below ambient air temperature under direct sunlight. Nature 515, 540-544 (2014). vol. 236 489-513 (2019). 
334 4. Mandal, J. et al. Hierarchically porous polymer coatings for highly efficient passive daytime radiative cooling. Science (80-. ). 362, 315-319 (2018).

337 5. Chae, D., Son, S., Liu, Y., Lim, H. \& Lee, H. High-Performance Daytime Radiative Cooler and Near-Ideal Selective Emitter Enabled by Transparent Sapphire Substrate. Adv. Sci. 7, 2001577 (2020).

340 6. Rephaeli, E., Raman, A. \& Fan, S. Ultrabroadband photonic structures to achieve high-performance daytime radiative cooling. Nano Lett. 13, 1457-

343 7. Chae, D. et al. Spectrally Selective Inorganic-Based Multilayer Emitter $1461(2013)$. for Daytime Radiative Cooling. ACS Appl. Mater. Interfaces 12, 8073$8081(2020)$.

8. Zhai, Y. et al. Scalable-manufactured randomized glass-polymer hybrid metamaterial for daytime radiative cooling. Science (80-. ). 355, 10621066 (2017).

349 9. Zhou, L. et al. A polydimethylsiloxane-coated metal structure for all-day radiative cooling. Nat. Sustain. 2, 718-724 (2019). 
10. Suichi, T., Ishikawa, A., Tanaka, T., Hayashi, Y. \& Tsuruta, K. Whitish daytime radiative cooling using diffuse reflection of non-resonant silica nanoshells. Sci. Rep. 10, 1-6 (2020).

11. Lee, D. et al. Sub-ambient daytime radiative cooling by silica-coated porous anodic aluminum oxide. Nano Energy 79, 105426 (2021).

12. Lee, G. J., Kim, D. H., Heo, S. Y. \& Song, Y. M. Spectrally and Spatially Selective Emitters Using Polymer Hybrid Spoof Plasmonics. ACS Appl. Mater. Interfaces 12, 53206-53214 (2020).

13. Didari, A. \& Mengüç, M. P. A biomimicry design for nanoscale radiative cooling applications inspired by Morpho didius butterfly. Sci. Rep. 8, $16891(2018)$.

14. Zhu, L., Raman, A., Wang, K. X., Anoma, M. A. \& Shanhui Fan, A. Radiative cooling of solar cells. (2014) doi:10.1364/OPTICA.1.000032.

15. Bhatia, B. et al. Passive directional sub-ambient daytime radiative cooling. Nat. Commun. 9, 1-8 (2018).

16. Son, S. et al. Colored emitters with silica-embedded perovskite nanocrystals for efficient daytime radiative cooling. Nano Energy 105461 (2020) doi:10.1016/j.nanoen.2020.105461. 
369 17. Lv, S. et al. A novel strategy of enhancing sky radiative cooling by solar photovoltaic-thermoelectric cooler. Energy 219, 119625 (2021).

18. Rajkhowa, R. Light Pollution and Impact of Light Pollution. International Journal of Science and Research www.ijsr.net.

373

19. Xiang, B. et al. 3D porous polymer film with designed pore architecture and auto-deposited $\mathrm{SiO} 2$ for highly efficient passive radiative cooling. Nano Energy 81, 105600 (2021).

20. Chen, Y. et al. Cellulose-Based Hybrid Structural Material for Radiative Cooling. Nano Lett. 21, 404 (2021).

21. Bijarniya, J. P., Sarkar, J. \& Maiti, P. Performance simulation of polymerbased nanoparticle and void dispersed photonic structures for radiative cooling. Sci. Rep. 11, 893 (2021).

22. Son, S., Liu, Y., Chae, D. \& Lee, H. Cross-Linked Porous Polymeric Coating without a Metal-Reflective Layer for Sub-Ambient Radiative Cooling. ACS Appl. Mater. Interfaces 12, 57839 (2021).

23. Sun, S., Li, C., Zhang, L., Du, H. \& Burnell-Gray, J. Interfacial structures and mechanical properties of PVC composites reinforced by $\mathrm{CaCO} 3$ with different particle sizes and surface treatments. Polym. Int. 55, 158-164 (2006). 
388 24. Chen, C.-H., Teng, C.-C., Su, S.-F., Wu, W.-C. \& Yang, C.-H. Effects of microscale calcium carbonate and nanoscale calcium carbonate on the fusion, thermal, and mechanical characterizations of rigid poly(vinyl chloride)/calcium carbonate composites. J. Polym. Sci. Part B Polym.

25. Liu, P., Zhao, M. \& Guo, J. Thermal Stabilities of Poly(Vinyl Phys. 44, 451-460 (2006).

26. Abdolmohammadi, S. et al. Enhancement of Mechanical and Thermal Properties of Polycaprolactone/Chitosan Blend by Calcium Carbonate Nanoparticles. Int. J. Mol. Sci. 13, 4508-4522 (2012).

27. Mizuno, M., Fukunaga, K., Saito, S. \& Hosako, I. Analysis of calcium carbonate for differentiating between pigments using terahertz spectroscopy. J. Eur. Opt. Soc. Rapid Publ. 4, 9044 (2009).

28. Sun, S., Ding, H. \& Hou, X. Preparation of CaCO3-TiO2 Composite Particles and Their Pigment Properties. Materials (Basel). 11, 1131 (2018). 
29. Deng, C.-M., Chen, M., Ao, N.-J., Yan, D. \& Zheng, Z.-Q. CaCO3/natural rubber latex nanometer composite and its properties. J. Appl. Polym. Sci. $101,3442-3447$ (2006).

30. Ahmad, W., Singh, B., Dalal, R. C. \& Dijkstra, F. A. Carbon dynamics from carbonate dissolution in Australian agricultural soils. Soil Res. 53, 144 (2015).

31. Rocha, D. B., Souza de Carvalho, J., de Oliveira, S. A. \& dos Santos Rosa, D. A new approach for flexible PBAT/PLA/CaCO 3 films into agriculture. J. Appl. Polym. Sci. 135, 46660 (2018).

32. Trushina, D. B., Bukreeva, T. V., Kovalchuk, M. V. \& Antipina, M. N. $\mathrm{CaCO} 3$ vaterite microparticles for biomedical and personal care applications. Mater. Sci. Eng. C 45, 644-658 (2014).

33. Fujiwara, M. et al. Encapsulation of proteins into $\mathrm{CaCO} 3$ by phase transition from vaterite to calcite. Cryst. Growth Des. 10, 4030-4037 (2010).

34. Suppes, G. J. et al. Calcium carbonate catalyzed alcoholysis of fats and oils. JAOCS, J. Am. Oil Chem. Soc. 78, 139-145 (2001). 
35. Chunxiang, Q., Jianyun, W., Ruixing, W. \& Liang, C. Corrosion protection of cement-based building materials by surface deposition of CaCO3 by Bacillus pasteurii. Mater. Sci. Eng. C 29, 1273-1280 (2009).

36. Galván-Ruiz, M., Hernández, J., Baños, L., Noriega-Montes, J. \& Rodríguez-García, M. E. Characterization of Calcium Carbonate, Calcium Oxide, and Calcium Hydroxide as Starting Point to the Improvement of Lime for Their Use in Construction. J. Mater. Civ. Eng. 21, 694-698 (2009).

37. Hossain, M. M. \& Gu, M. Radiative cooling: Principles, progress, and potentials. Advanced Science vol. 3 (2016).

38. Aili, A. et al. A kW-scale, 24-hour continuously operational, radiative sky cooling system: Experimental demonstration and predictive modeling. Energy Convers. Manag. 186, 586-596 (2019).

39. Zhao, D. et al. Subambient Cooling of Water: Toward Real-World Applications of Daytime Radiative Cooling. Joule 3, 111-123 (2019).

40. Liu, J. et al. Sub-ambient radiative cooling with wind cover. Renew. Sustain. Energy Rev. 130, 109935 (2020).

41. Liu, J. et al. Performance evaluation of various strategies to improve subambient radiative sky cooling. Renew. Energy 169, 1305-1316 (2021). 
(a)
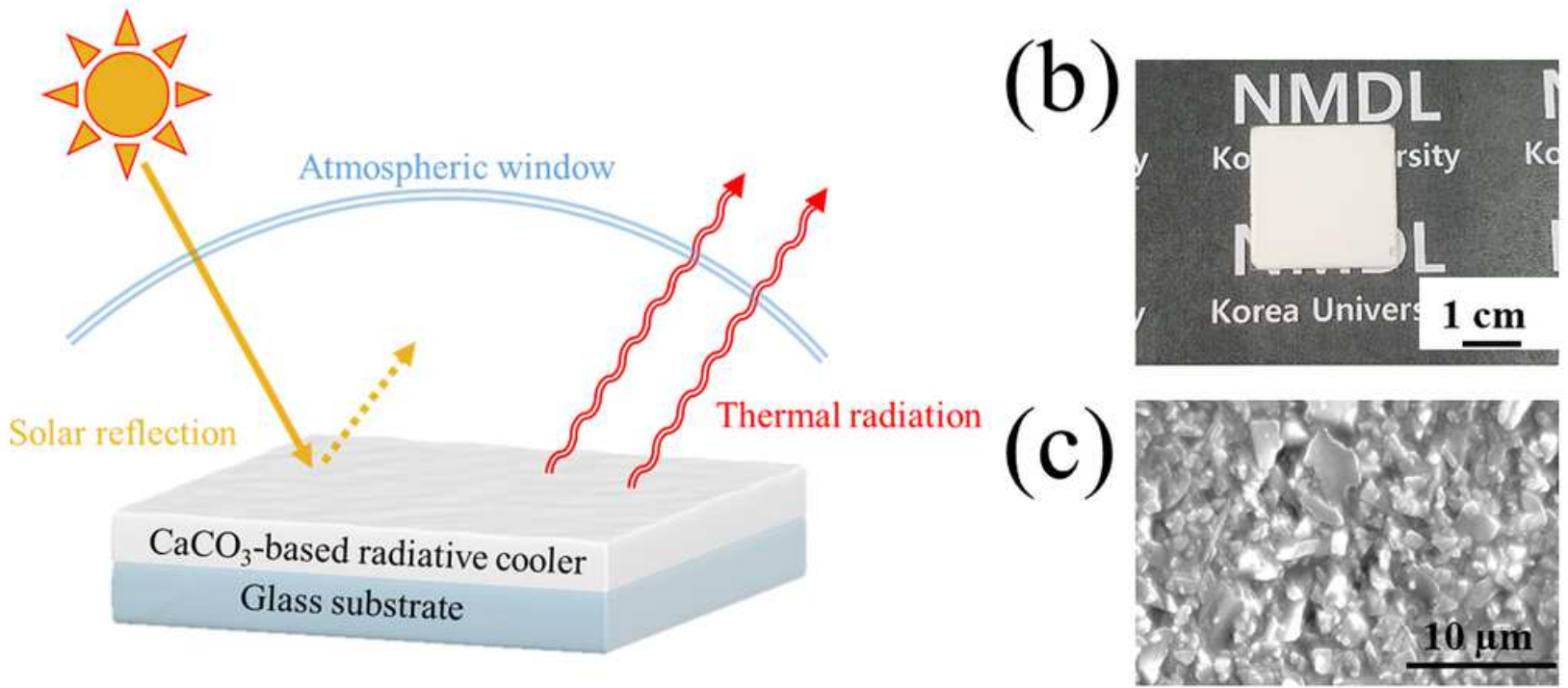

Figure 1

(a) Schematic of radiative cooling principle and radiative cooler structure. (b) Photo image and (c) SEM top view of radiative cooler, CaCO3-coated glass.

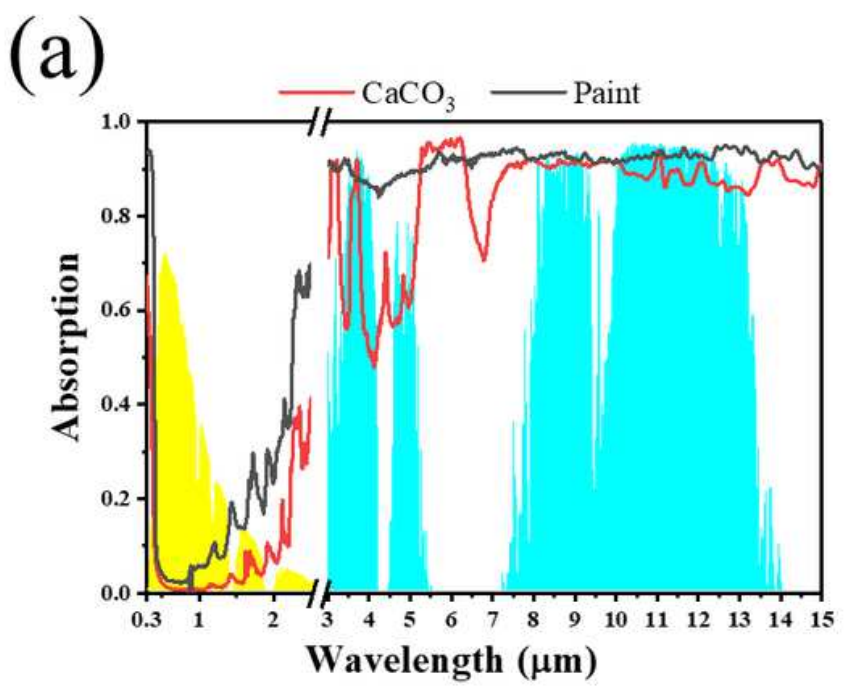

(b)

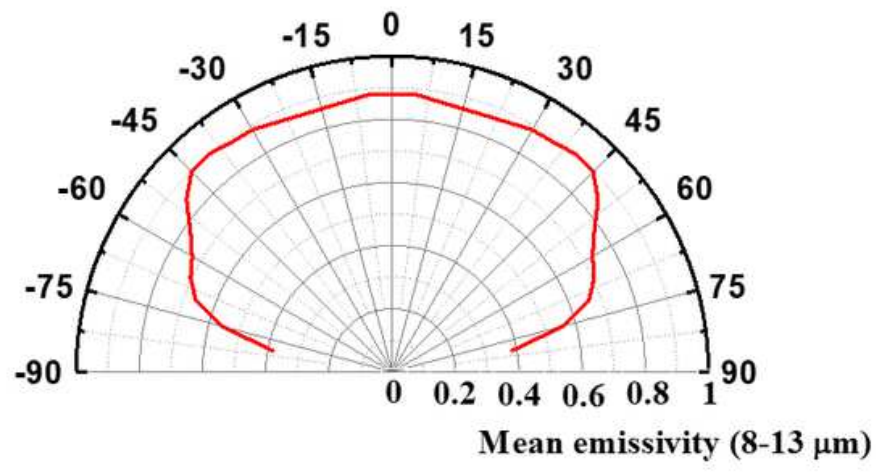

Figure 2

(a) Spectral absorptivity and emissivity of CaCO3- and commercial white-paint-coated glass. (b) Average emissivity of CaC03-coated glass in the atmospheric window $(8-13 \mu \mathrm{m})$ with respect to angle $\theta$. 


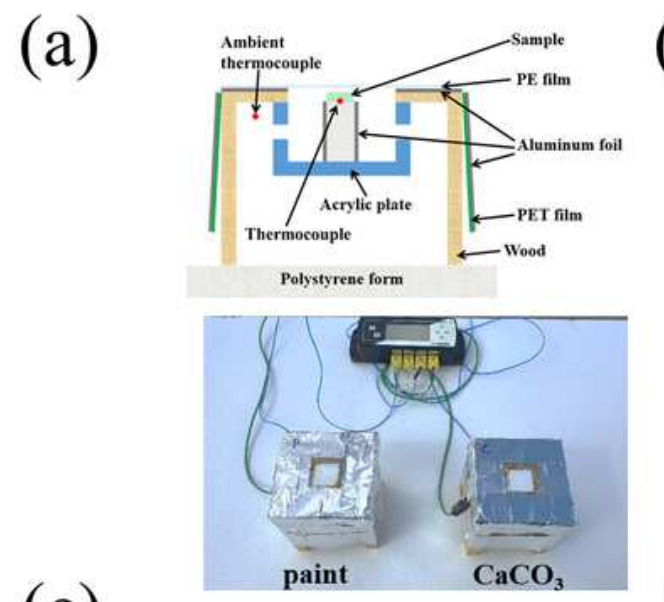

(b)
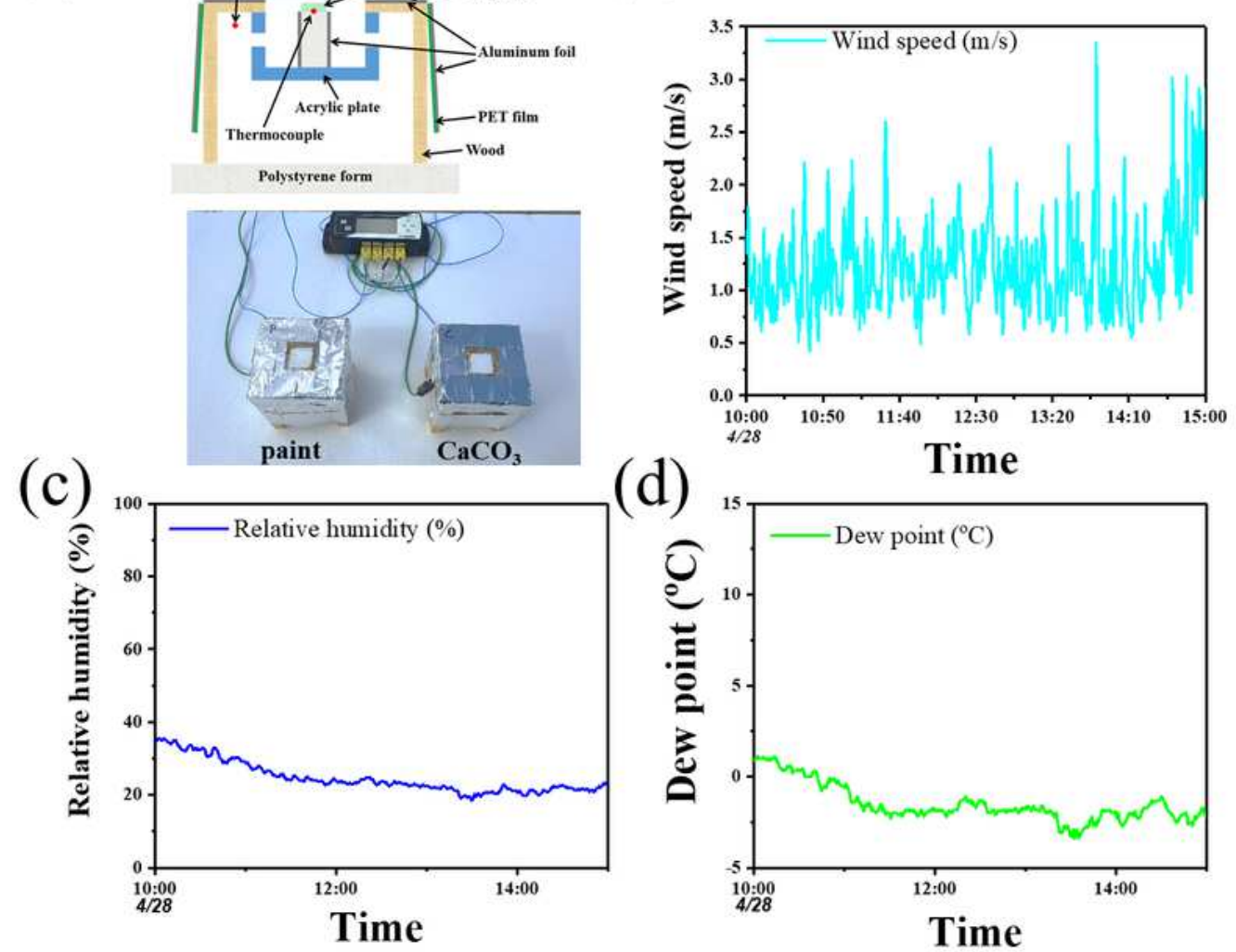

(d)

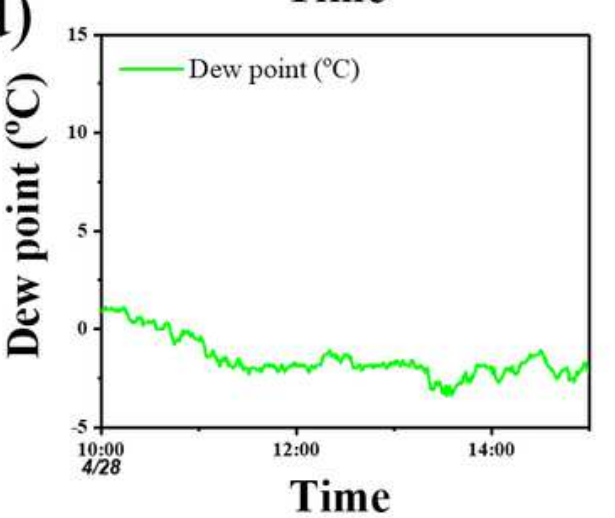

(e)

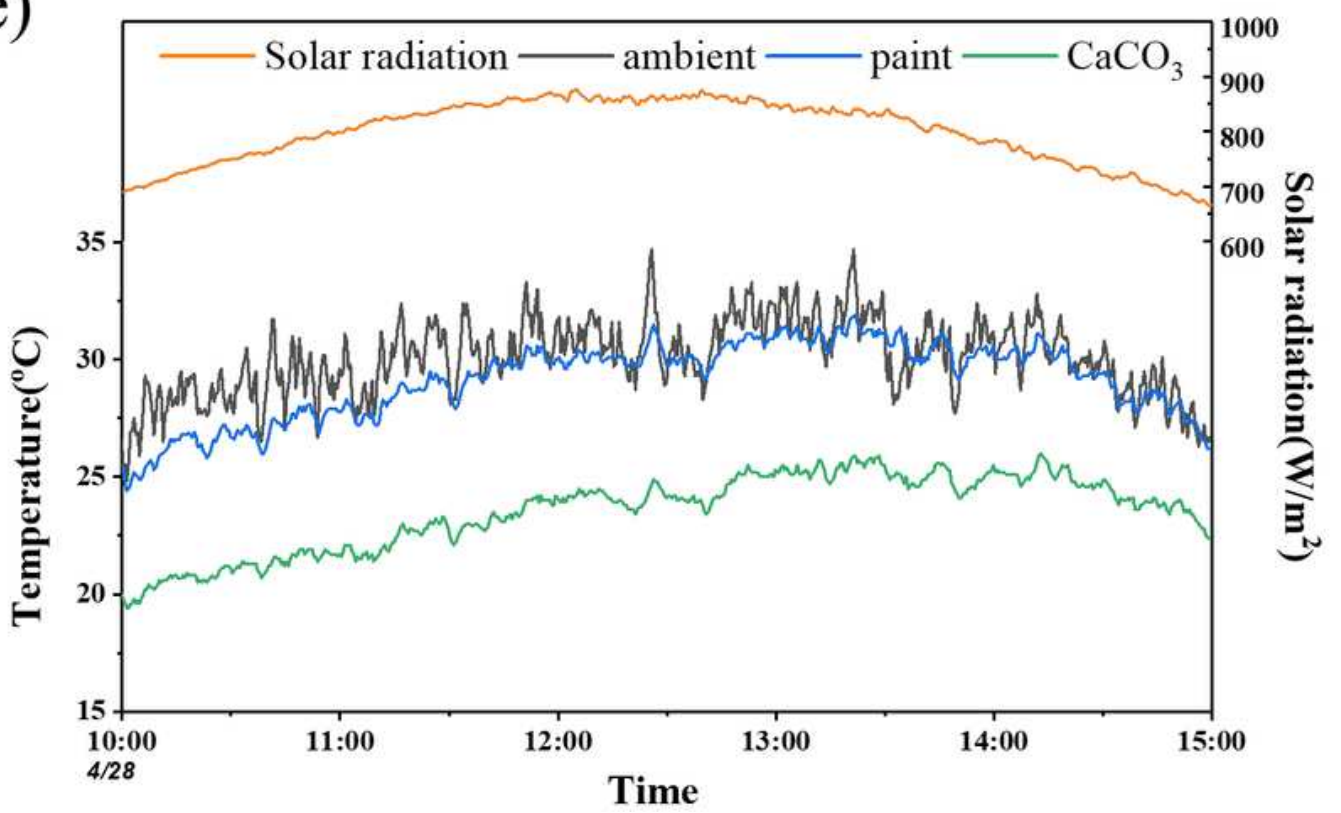

\section{Figure 3}

(a) Schematic diagram and photo image of outdoor measurement system for radiative cooling. Environmental conditions (b) wind speed, (c) Relative humidity, (d) dew point. (e) Radiative cooling performance of $\mathrm{CaCO} 3$ and white paint in terms of temperature in daytime. 
(a)

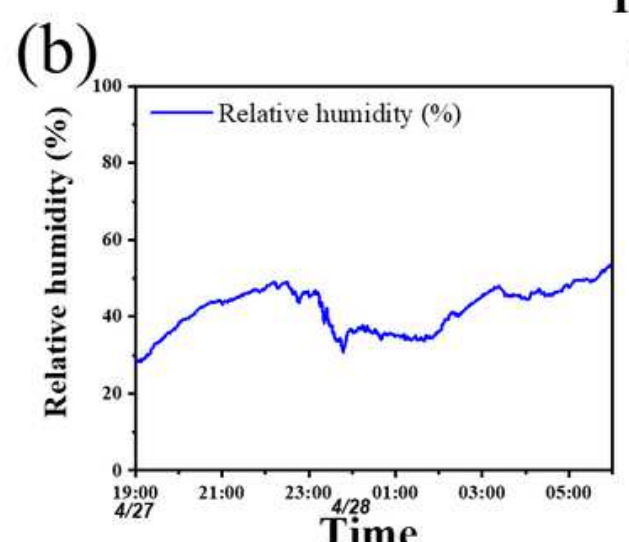

Time

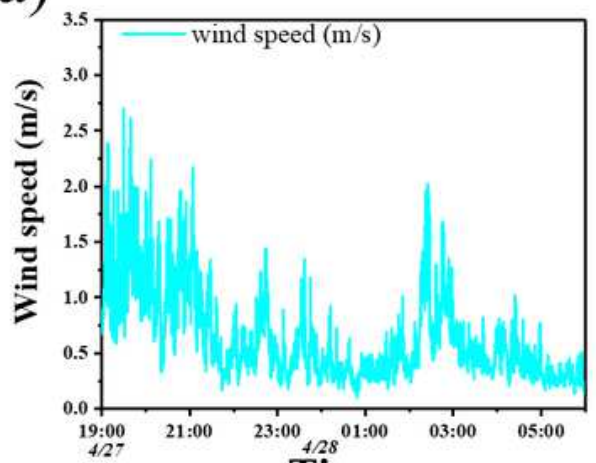

Time

(c)

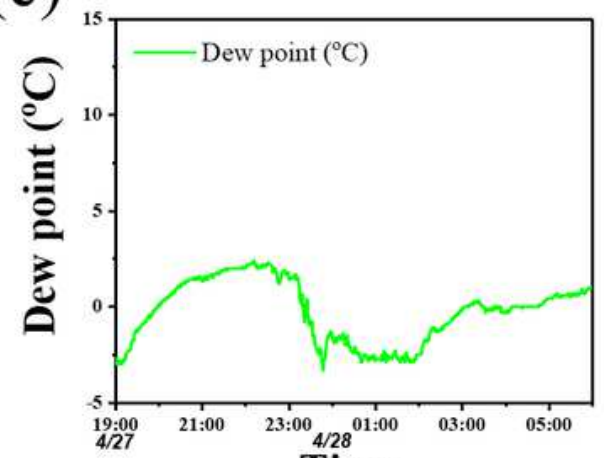

Time

(d)

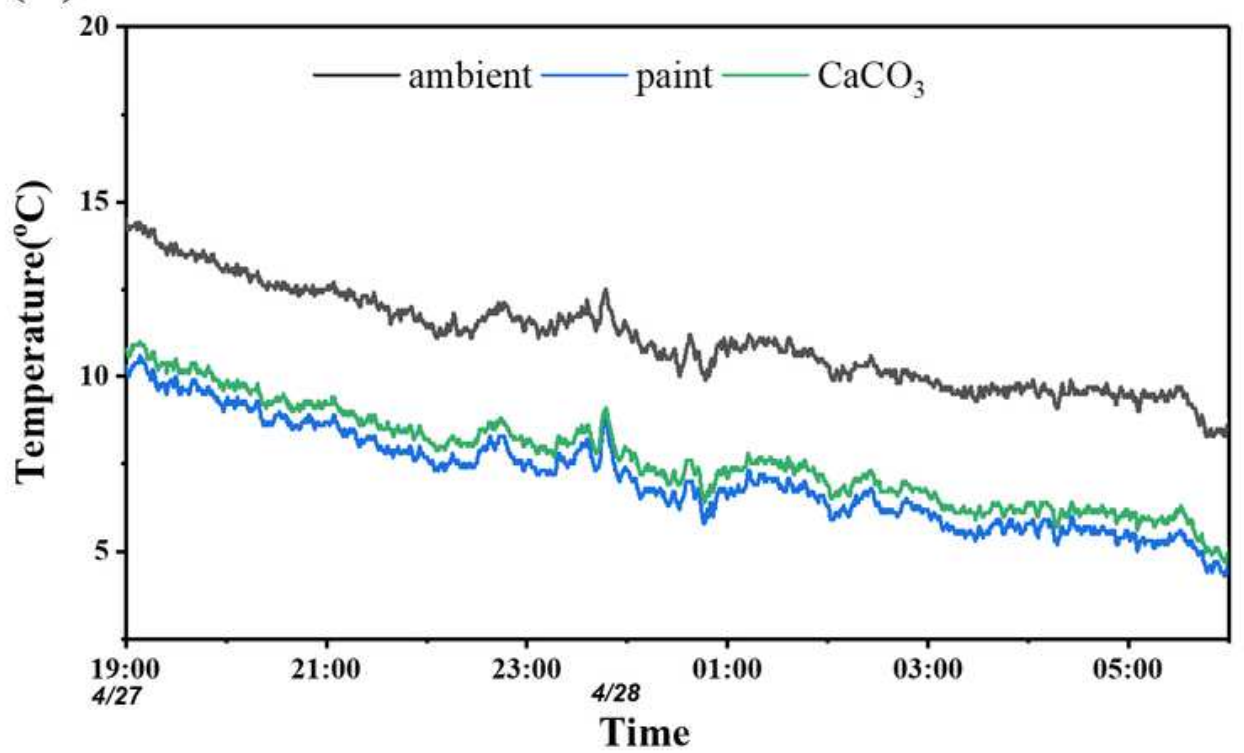

Figure 4

Environmental conditions (a) wind speed, (b) Relative humidity, (c) dew point. (d) Radiative cooling performance of $\mathrm{CaCO} 3$ and white paint in terms of temperature in nighttime. 
(a)
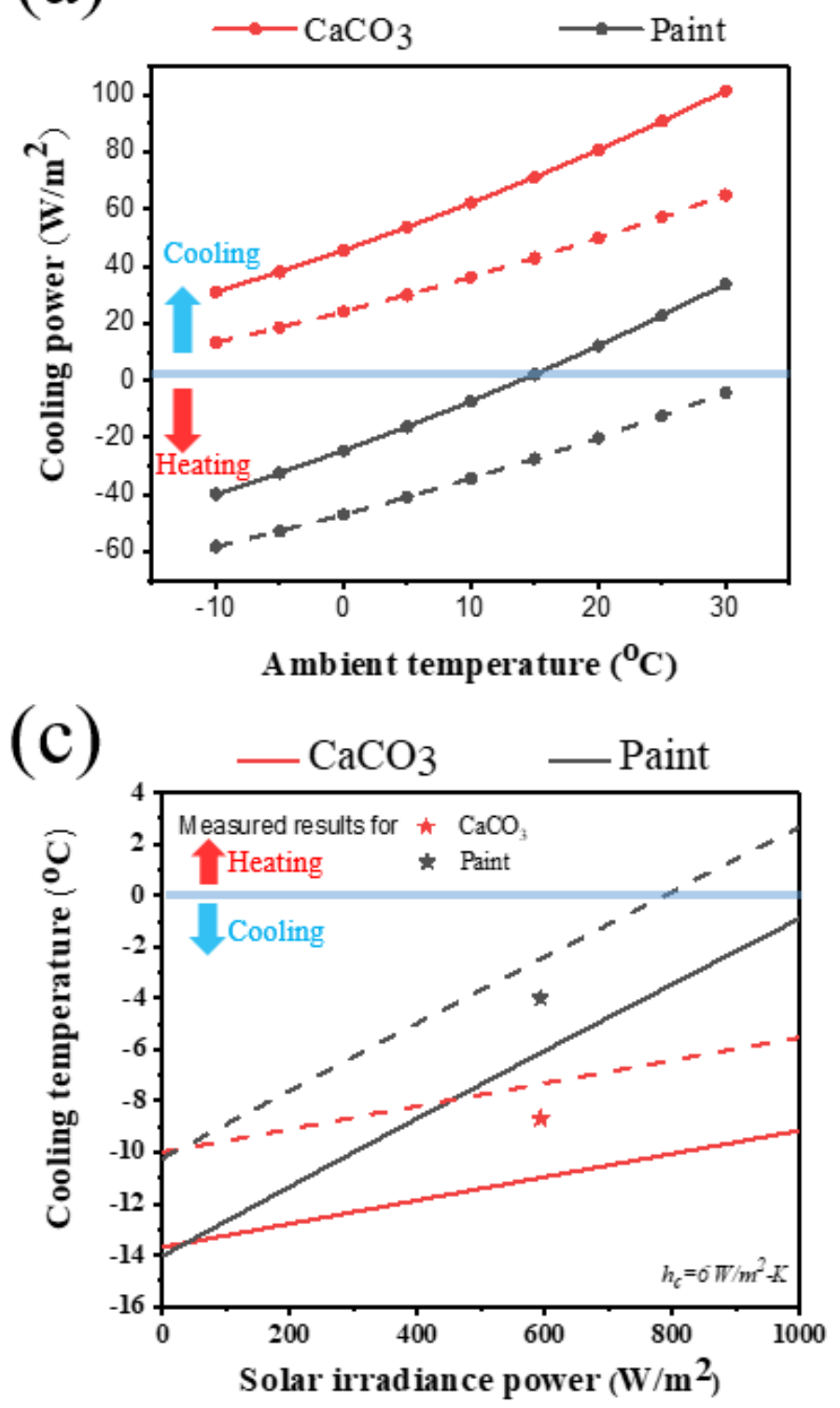

(b)

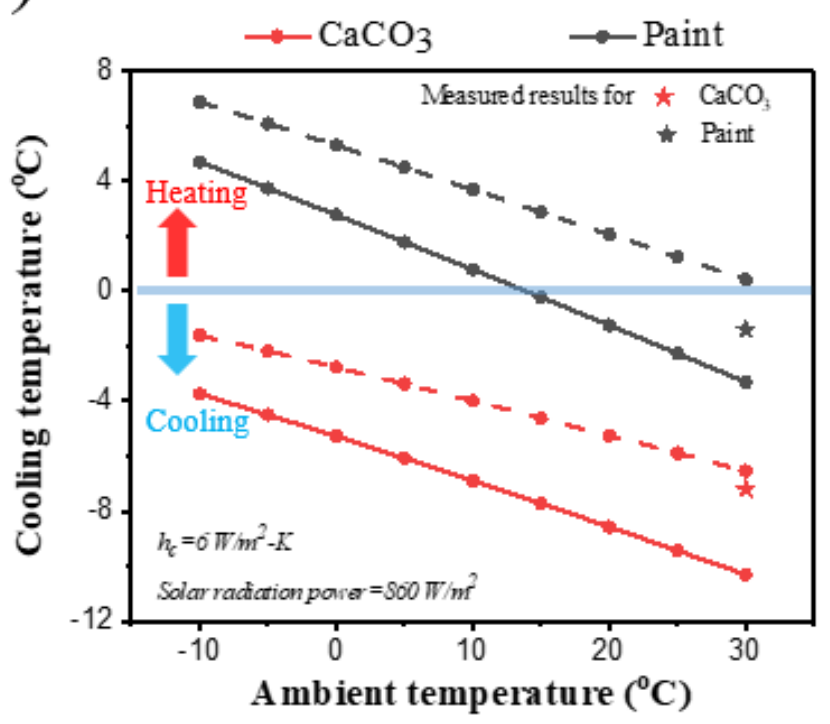

(d)

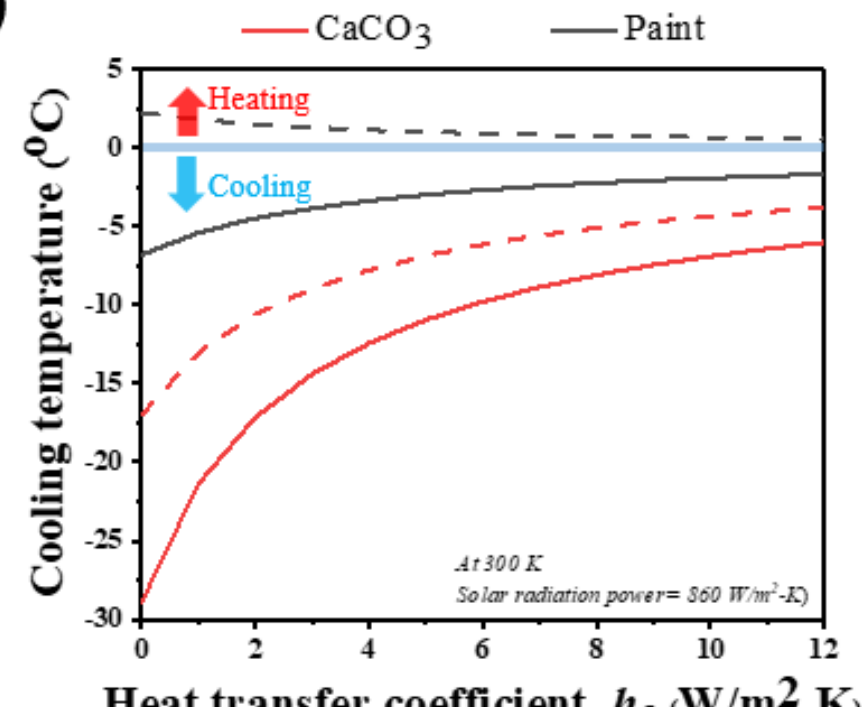

Figure 5

(a) Calculated cooling power of $\mathrm{CaCO} 3$ and (b) cooling temperature in accordance with ambient temperature under the condition of $\mathrm{hc}=6 \mathrm{~W} / \mathrm{m} 2-\mathrm{K}$ using ideal (solid line) and mid-latitude winter (dotted line) atmospheric transmittance and measured cooling temperatures are represented with stars (red for $\mathrm{CaCO3/glass,} \mathrm{gray} \mathrm{for} \mathrm{paint/glass).} \mathrm{(c)} \mathrm{Calculated} \mathrm{temperatures} \mathrm{of} \mathrm{CaCO}-$ and paint-coated glass in accordance with the solar irradiance power under the condition of hc $=6 \mathrm{~W} / \mathrm{m} 2-\mathrm{K}$ and measured cooling temperatures are marked with stars (red for $\mathrm{CaCO} 3$, gray for paint). (d) Calculated temperatures of CaCO3- and paint-coated glass in accordance with convection coefficient hc at $300 \mathrm{~K}$ using AM1.5 solar irradiance spectrum using ideal (solid line) and mid-latitude (dotted line) atmospheric transmittance.

\section{Supplementary Files}


This is a list of supplementary files associated with this preprint. Click to download.

- supporting.docx

- Graphicalabstract.png 